\title{
A Patchwork of Streptomyces Species Isolated from Potato Common Scab Lesions in North America
}

\author{
Leslie A. Wanner
}

Published online: 23 May 2009

(C) Potato Association of America 2009

\begin{abstract}
To determine distribution and prevalence of Streptomyces species associated with common scab in North America, more than 1,400 isolates were made from scabby potato tubers. Samples were obtained from locations across the continent, and from multiple sites in close geographic proximity. Most potentially pathogenic isolates belonged to four species previously associated with common scab, S. scabies, S. europaeiscabiei, S. stelliscabiei, and $S$. sp. IdahoX. Additionally, small numbers of potentially pathogenic isolates were identified as $S$. acidiscabies, $S$. turgidiscabies and six additional ribotypes. S. europaeiscabiei was most common in the west and $S$. scabies predominated in the middle and eastern Midwest. Beyond this geographic trend, species distribution was patchy. A single species often predominated in a field while neighboring fields had different species. Local and regional variation was seen when isolates were genotyped for repetitive sequence element patterns, reflecting the conserved or core genome, and genes characteristic of the Streptomyces pathogenicity island, reflecting flexible components of the Streptomyces genome. This is the largest survey to date of the distribution of common scab-causing species, and will be a resource for population biology studies and for tracing the evolutionary history and spread of common scabassociated Streptomyces.
\end{abstract}

Resumen Para determinar la distribución y prevalencia de especies de Streptomyces asociadas con la sarna común en

L. A. Wanner $(\bowtie)$

United States Department of Agriculture Agricultural Research

Service, Genetic Improvement of Fruits and Vegetables Laboratory, 10300 Baltimore Ave.,

Beltsville, MD 20705, USA

e-mail: Leslie.Wanner@ars.usda.gov
Norteamérica, se hicieron más de 1,400 aislamientos de tubérculos de papa con sarna. Las muestras fueron obtenidas de localidades de todo el continente y de múltiples lugares geográficamente próximos. Los aislamientos potencialmente más patogénicos fueron de cuatro especies previamente asociadas con sarna común, S. scabies, S. europaeiscabiei, S. stellicabiei y $S$. sp. IdahoX. Adicionalmente, un número pequeño de aislamientos potencialmente patogénicos fueron identificados como $S$. acidiscabies, $S$. turgidiscabies y seis ribotipos adicionales. $S$. europaeiscabiei fue el más común en el oeste y $S$. scabies predominó en el centro y este del Medio Oeste. Más allá de esta tendencia geográfica, la distribución de especies fue en parches. Una sola especie a menudo predominó en un campo mientras en los campos vecinos se encontraron diferentes especies. Se vieron variaciones locales y regionales cuando a los aislamientos se les determinó el genotipo para patrones de elementos con secuencias repetitivas que reflejan el genoma conservado o central, y genes característicos de la isla de patogenicidad de Streptomyces, reflejando componentes flexibles del genoma de Streptomyces. Este es la pesquisa más extensa a la fecha sobre la distribución de las especies que causan sarna común, y será un recurso para estudios de biología poblacional y para determinar la historia evolutiva $\mathrm{y}$ diseminación de Streptomyces asociado a la sarna común.

Keywords Streptomyces scabies · Population genetics · Pathogenicity island

\section{Abbreviations}

CS Common scab

PAI Pathogenicity island

PCR Polymerase chain reaction

RFLP Restriction fragment length polymorphism

txtAB Gene (operon) encoding thaxtomin synthetase 


\section{Introduction}

Common scab (CS) of potato, caused by a complex of soil bacteria in the genus Streptomyces, is one of the most important potato diseases in North America (Hill and Lazarovits 2005; Loria et al. 2006). It reduces crop value and, in extreme cases, yield (Hiltunen et al. 2005). Although CS has been a persistent world-wide problem in potato production for more than a century, few environmentally acceptable control methods are available, and little progress has been made in improving disease control or plant disease resistance.

Plant disease results from the interaction between the plant, environmental conditions, and the pathogen. In the case of CS, the result of this three-way interaction is large differences in CS incidence and severity from region to region, from field to field within regions and from year to year in the same field, complicating efforts to understand the contribution of each component of the plant disease triangle. Commonly-grown commercial potato varieties differ in their susceptibility to CS (Goth et al. 1993, Haynes et al. 1997; Lambert et al. 2006; Powelson et al. 1993; Wanner et al. 2006), but none is completely resistant (or tolerant). In addition to genetic differences between potato varieties, environmental factors including soil moisture and $\mathrm{pH}$ seem to play a role in the variability in CS incidence and severity in different years and locations. Some of these factors form the basis for widely employed (if variably effective) disease control strategies, such as maintaining high soil moisture levels during early tuber development (Powelson et al. 1993). Differences in the CS susceptibility of individual potato varieties grown in different locations have been noted (Wanner et al. 2006). Some of this variation can be attributed to climatic differences, while some of this location-specific variation in CS response in individual potato varieties could be attributable to the soil microflora, and particularly, to differences in pathogen populations.

Streptomyces is a very large genus of mostly saprophytic soil-swelling bacteria, best-known as the source of more than half of antibiotics and a host of other anti-inflammatory, immune-suppressive and antimicrobial compounds (Hopwood 2006). Streptomyces species are ubiquitous and abundant in soils (Janssen 2006; Pierzynsk et al. 2005), and may be present at $10^{6}$ organisms per cubic centimeter of soil. Plant pathogenicity in the genus is based on a toxin, thaxtomin, which is produced by pathogenic strains. Genes encoding enzymes for biosynthesis of thaxtomin are clustered in the chromosome in several Streptomyces species in a pathogenicity island (PAI) (Loria et al. 2006), and this PAI can be transferred from bacterium to bacterium, including between different species (horizontally transferred), creating new pathogenic strains or species (Loria et al. 2006). Despite the potential for horizontal acquisition of a PAI, pathogenic species or strains comprise a small percentage of the more than 400 described species in the genus. In small collections of pathogenic Streptomyces isolated from several geographic locations around the world, about ten Streptomyces species have been found to harbor all or some part of the S. scabies PAI (Loria et al. 2006).

The best-known species, $S$. scabies, seems to be cosmopolitan in distribution, though several recent reports indicate that it is infrequent in Europe (Bouchek-Mechiche et al. 2000; Flores-González et al. 2008; Kreuze et al. 1999). The most frequent species in northern Europe is S. europaeiscabiei (Flores-González et al. 2008). S. stelliscabiei has been reported from France and the USA (Bouchek-Mechiche et al. 2000; Wanner 2006). Phylogenetically more distant CS-causing species are known from multiple regions, including S. turgidiscabies in Japan and Finland (Kreuze et al. 1999; Miyajima et al. 1998), and S. acidiscabies from Maine, Korea and Japan (Lambert and Loria 1989a; Song et al. 2004; Tóth et al. 2001). Unique species have been described from Korea (Park et al. 2003a, b). In North America, three distinct groups or species have been differentiated in eastern Canada (Goyer et al. 1996), and four species of scab-causing Streptomyces were found from nine locations in six US states (Wanner 2006). A new group of scab-causing Streptomyces was identified in Idaho (Wanner 2007b), suggesting that greater species diversity may exist. Numerous other species have been mentioned throughout the years, primarily before the advent of molecular methods of species determination. In addition to different CS-causing species, pathogenic strains can differ in the content of three marker genes from the Streptomyces PAI (Wanner 2006).

The goal of the present study was to map the species distribution and PAI genotypes of Streptomyces associated with CS lesions in most of the potato-growing region of North America. Streptomyces isolates obtained during this study were genetically characterized by examining the ribosomal DNA sequence type (as an indicator of species affiliation) and combinations of genes characteristic of the Streptomyces pathogenicity island (PAI genotypes). In addition, core genome similarity was examined in isolates classified as the same species (based on ribosomal DNA sequence type) using repetitive sequence element PCR. The picture that emerges is that a small number of closelyrelated species can typically be isolated from CS lesions on potatoes in North America. Twelve different 16S rDNA types (species) were found, but five species accounted for $98 \%$ of the pathogenic isolates. Two species found were not previously associated with CS in North America. There are general geographic trends in species distribution across the continent, overlaid with a patchwork of local species variation on a smaller geographic scale. This is the largest systemic effort to map differences in Streptomyces associated with $\mathrm{CS}$ in different regions. 
The collection established and maintained in this study serves as a base for population genetics studies of CSassociated Streptomyces. These data also provide a baseline to determine whether populations of scab-causing streptomycetes are shifting within the USA and Canada over time; it is possible that changes in the profile of CS-causing streptomycetes may affect CS incidence and severity. Local and regional knowledge of the populations of CS-causing Streptomyces should be useful in developing better management strategies and variety recommendations for growers, and is essential in developing CS-resistant potato varieties.

\section{Materials and Methods}

Sources of Plant Material This study was made possible by the willingness of many people in the potato community to supply scabby potato tubers, and their contribution is gratefully acknowledged. Potato tubers with typical CS lesions were sent to the laboratory in Beltsville by Walter R. Stevenson, Department Plant Pathology, University of Wisconsin; John Nordgaard and many agronomists at Black Gold Farms in ND, IN, MI, TX, NE, MO, FL, NC; Steve Johnson, University of Maine Cooperative Extension Service, Presque Isle, ME; Christian Thill, Jeff Miller, Department of Horticultural Sciences, University of Minnesota; Dave Douches, Elise Hollister, Michigan State University; Jonathan Whitworth, Rich Novy, USDA-ARS, Aberdeen, ID; Jeff Miller, University of Idaho Research and Extension Center, Aberdeen, ID; Eugenia Banks, Ontario Ministry for Food, Agriculture and Rural Affairs, Guelph, Ontario; Bruce Atkinson, Atkinson Farms, Alliston, Ontario; Barbara Daniels-Lake, Agriculture and AgriFood Canada, Nova Scotia; Walter de Jong, Ken Paddock; Department of Plant Breeding \& Genetics, Cornell University; Chuck Bornt, Cornell Cooperative Extension Service, Troy New York; Sandra Menasha, Suffolk County Cooperative Extension Association, Riverhead New York; Alberto Pantoja, United States Department of Agriculture Agricultural Research Service, Subarctic Agricultural Research Unit, Fairbanks, AK; Joe Kuhl United States Department of Agriculture, Agricultural Research Service, Subarctic Agricultural Research Unit, Palmer, AK; William Campbell, Department of Natural Resources, Palmer, AK; Phil Hamm and staff, Agriculture Research \& Extension Center, Oregon State University; Donald Halseth, Eric Sansted, Department of Horticulture, Cornell University; Barbara Christ, Department of Plant Pathology, Pennsylvania State University; Andy Jensen, Washington State Potato Commission, Moses Lake, WA; Duane Preston, Horticultural Science Department University of Minnesota, E. Grand Forks, MN.
Isolation and Preservation of Isolates

Streptomycetes were isolated from scabby potato tubers from 135 locations in 24 US states and Canadian provinces. Locations are given in Fig. 1 and mapped in Fig. 2. Isolation, storage, and DNA preparation procedures have been described (Wanner 2004, 2006, 2007b). Data presented here are derived from 511 independent isolations, from which 1,471 isolates were molecularly characterized. Records were made of the precise source, potato cultivar, appearance of the scab lesion and any additional details on field or cultural conditions that were provided with the samples from which isolations were made, as well as on the morphology of each preserved isolate on water agar, yeastmalt extract agar, and peptone-yeast extract-iron agar. These records are maintained for a growing research collection of Streptomyces isolates now numbering over 2000, and are available from the author. A few of the isolates have been previously described (Wanner 2004, 2006, 2007b).

Determination of Potential Pathogens and Pathogenicity Test Results

Isolates were classified as potential pathogens by PCR with primer pair txtAB1 and txtAB2, as described below. Sixtythree of the isolates described here were tested for pathogenicity using plant assays in potatoes or/and radishes (Wanner 2004, 2007b). DNA preparations from CS lesions from which no txtAB-positive streptomycetes were obtained were also subjected to PCR with primers Rs2R1 and Rs1F2 (Lees et al. 2002), specific to the potato stem canker and black scurf pathogen Rhizoctonia solani AG3, which can also cause lesions on tubers. No positives were detected.

\section{Characterization of rDNA Genotype}

Genotypes at variable regions in the $16 \mathrm{~S}$ rDNA (rDNA) gene were determined by PCR using the primer pairs previously described (Wanner 2006), plus two new primer pairs (Table 1). Initially, the source of Taq DNA polymerase and reaction conditions were as described (Wanner 2006), but part way through the study, the source of Taq DNA polymerase and PCR buffer was changed to GoTaq Flexi DNA polymerase (Promega, Inc., Madison, WI). This necessitated modification of the amplification conditions, and the currently-used conditions for all primer pairs reported here are listed in Table 1. A primer pair recognizing the species $S$. aureofaciens, described as causing netted scab in Finland (Kreuze et al. 1999), was also applied to all isolates for which no other primer pairs produced an amplicon, but no positives were found. 
To distinguish $S$. scabies from S. europaeiscabiei (Flores-González et al. 2008), which have near-identical $16 \mathrm{~S}$ rDNA sequences, the ribosomal intergenic spacer was amplified using primers ITS-R and ITS-L (Song et al. 2004) under the conditions in Table 1, and the ITS amplicon was subsequently digested with the restriction enzyme Hpy99I (New England Biolabs, Beverly, MA) for $2-3 \mathrm{~h}$ at $37^{\circ} \mathrm{C}$ in the buffer recommended by the manufacturer. Products of all PCR reactions were separated on $1.5 \%$ agarose gels run in TBE buffer (Sambrook et al. 1982), and visualized by staining with ethidium bromide. Amplicon sizes were determined by comparison with appropriate DNA size markers (purchased from Promega Corp., Madison, WI, and Bioline USA Inc., Randolph, MA).

For several isolates, the entire 16S rDNA gene was amplified using primer pair $16 \mathrm{~S}-1 \mathrm{~F}$ and $16 \mathrm{~S}-1 \mathrm{R}$, cloned and sequenced as described (Wanner 2006). Sequencing was performed by Macrogen, Inc. (Seoul, South Korea), using eight primers listed in Table 1, and sequences were assembled using the Contig Express program in Vector NTI Advance, version 10 from Invitrogen Corp. (Carlsbad, CA). Sequences were compared to the GenBank nr database using the BLAST algorithm (Zhang et al. 2000). The following new 16S rDNA sequences were obtained during the course of this work: $S$. europaeiscabiei isolates ID06-18B; S. stelliscabiei isolates WI04-08A, WI04-09A, ME06-36, PA06-2D, WI06-15D, WI06-6E; S. species IdahoX isolates TX07-01D, ID05-8D; ribotype (3), 6, 7 isolates NE06-02D, NE06-02F, ND05-01C, ND05-3B, ND05-13A; S. acidiscabies isolate NB05-2F; S. turgidiscabies isolates WI04-05A, WI04-05B; and ribotype 5 isolate NY05-11A. All are putative pathogenic isolates based on presence of the txtAB operon. New sequences derived during this study are deposited in GenBank under accession numbers FJ546725- FJ546742.

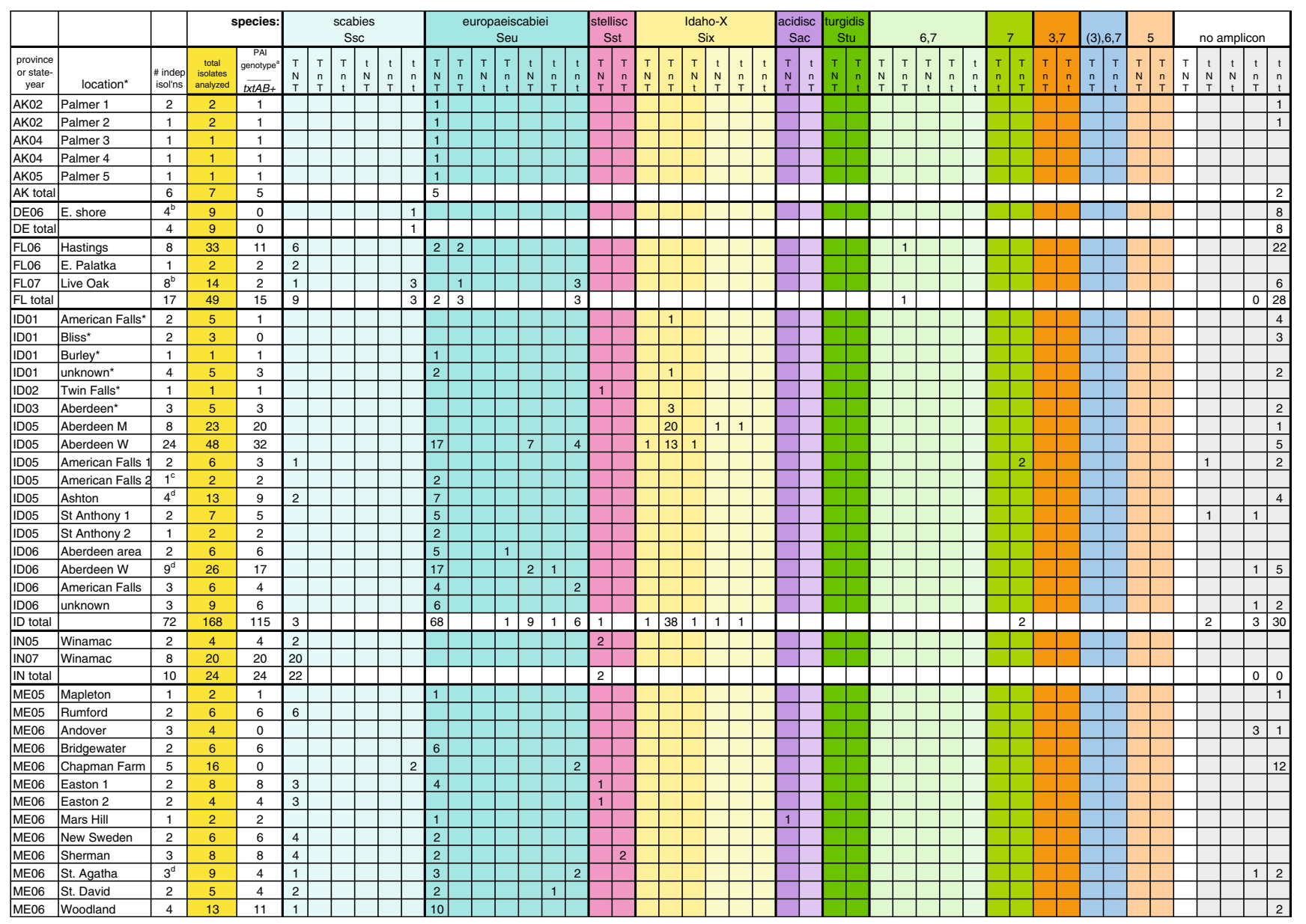

Fig. 1 Species (or ribotypes) and PAI patterns of streptomycetes isolated from CS lesions in 135 locations across North America. Isolates are organized by state or province of origin. Each field location and year of isolation is a line. The numbers of independent isolations (from a CS lesion on an individual tuber), the total number of isolates genotyped from each location, and the number of txtAB+ (presumably pathogenic) isolates are given for each field location, followed by the genotypes found. Individual species or ribotypes are grouped in column blocks of the same color, with a separate internal column for each PAI genotype found. PAI genotype designations: first $\mathrm{T} / \mathrm{t}$, presence/absence of $t x t A B$; second $\mathrm{N} / \mathrm{n}$, presence/absence of necl; third $\mathrm{T} / \mathrm{t}$, presence/absence of tomA. Lighter-shaded columns, txtAB(presumably non-pathogenic) 


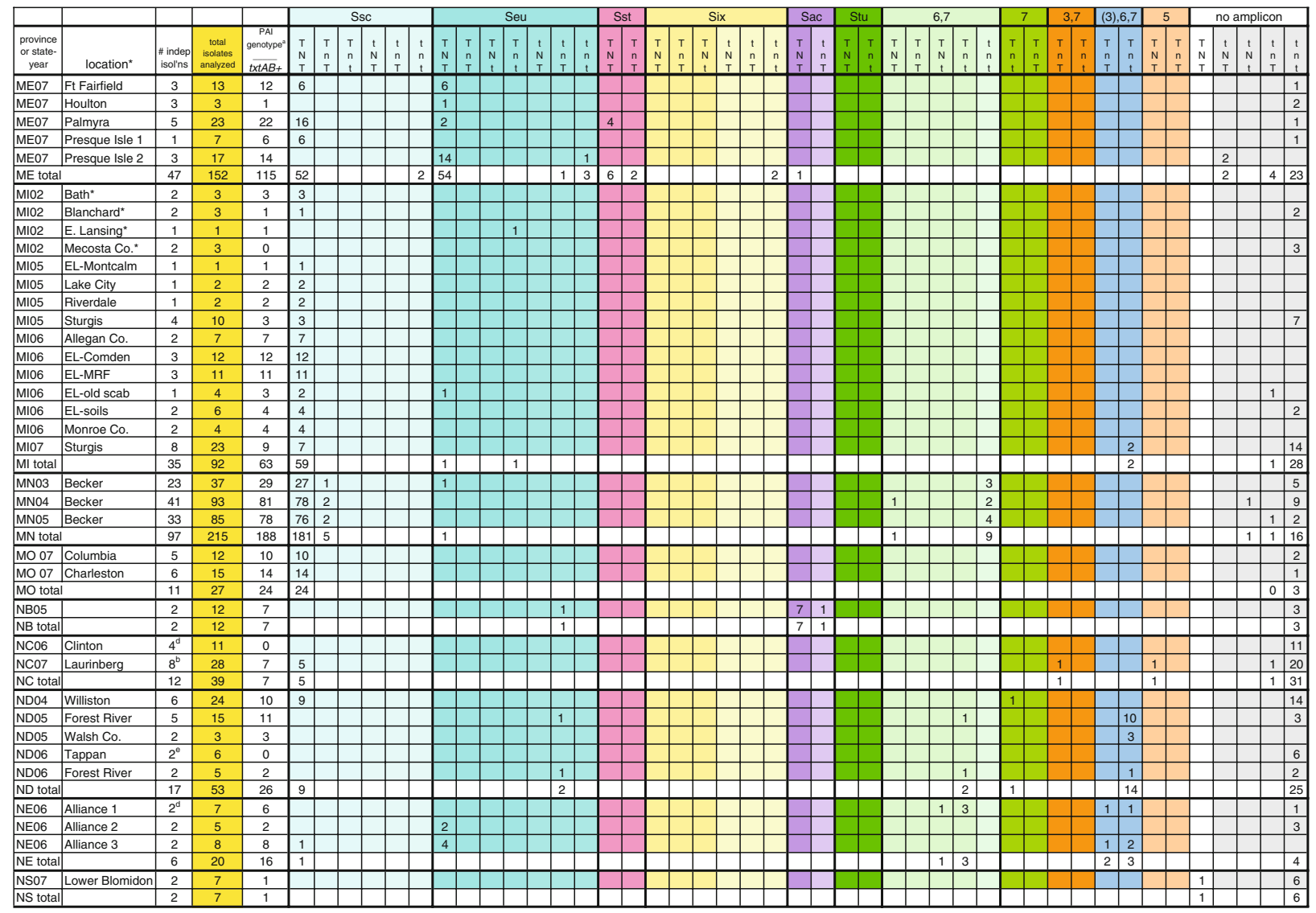

Fig. 1 (continued)

\section{Genotypic Characterization of the Streptomyces PAI}

DNA preparations and PCR with primers txtAB1 and txtAB2, tom3 and tom 4 and NF and NR (Bukhalid et al. 1998) were as described (Wanner 2006) with the modifications in Table 1. Primers were purchased from Integrated DNA Technologies (Coralville, IA). All PCR reactions were conducted in a Perkin-Elmer model 480 PCR machine, and were initiated with $5 \mathrm{~min}$ denaturation at $95^{\circ} \mathrm{C}$, followed by 35 cycles of $20 \mathrm{sec}$ at $95^{\circ} \mathrm{C}, 30 \mathrm{sec}$ at annealing temperature (Table 1) and $2 \mathrm{~min}$ extension at $72^{\circ} \mathrm{C}$. After completion of thermocycles, reactions were held at $4^{\circ} \mathrm{C}$. PCR products were separated on $1.5 \%$ agarose gels run in TBE buffer, and visualized by staining with ethidium bromide. Molecular weight standards (purchased from Promega, Inc., Madison, WI) were included on all gels to ascertain product sizes.

\section{Genomic Characterization by BOXA1R PCR}

PCR using the BOXA1R primer was performed in $25 \mu \mathrm{l}$ containing Green Go-Taq Flexi PCR buffer, $4 \mathrm{mM} \mathrm{MgCl}{ }_{2}$,
$0.75 \mathrm{mM}$ each dNTP, 25 pmol BOXA1R primer, 2.5 units GoTaq Flexi DNA polymerase (Promega Corp., Madison, WI), and approximately $5 \mathrm{ng}$ each DNA template. After initial template denaturation at $95^{\circ} \mathrm{C}$ for $5 \mathrm{~min}, 40$ temperature cycles of $20 \mathrm{sec}$ at $95^{\circ} \mathrm{C} / 30 \mathrm{sec}$ at $46^{\circ} \mathrm{C} / 3 \mathrm{~min}$ at $72^{\circ} \mathrm{C}$, followed by a hold at $4^{\circ} \mathrm{C}$ were conducted in a Perkin-Elmer model 480 PCR machine. Reactions were diluted with an equal volume of $1 \mathrm{X}$ load dye (Promega Corp., Madison, WI) before products were separated by electrophoresis in a $1.5 \%$ agarose gel.

\section{Results}

Streptomycetes were isolated from CS lesions on potato tubers provided by potato researchers and extension personnel in major potato production regions of the United States and Canada. Samples were obtained from a wide geographic range as well as multiple locations in close proximity to examine both regional and local variation in species associated with CS. Isolates came from 135 field locations distributed among 24 states and provinces. An 


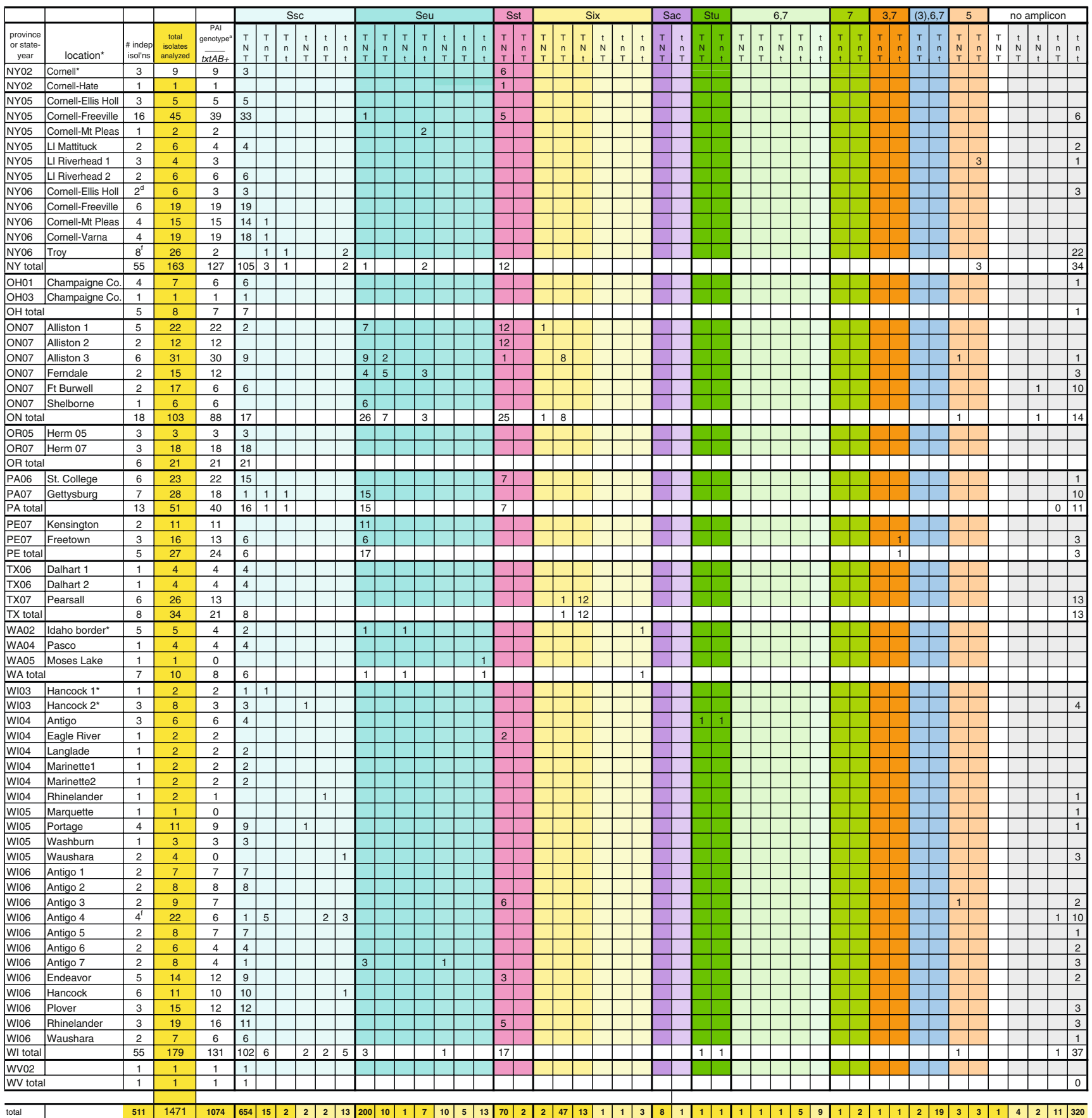

*included in Wanner, 2006

presence of genes associated with the Streptomyces PAl: first $T=t x t A B$ present, $t=t x t A B$ absent; $N=n e c 1$ present, $n=n e c 1$ absent; second $T=$ tomA present, $t=$ tomA absent

${ }^{b} \mathrm{txtAB}$ gene detected at a very low level in DNA preparation of only 1 (of 4-8) scabby potato tissue pieces used for isolation

ctxtAB gene not detected in DNA prepared from scabby potato tissue pieces used in isolation, although a few txtAB+ isolates obtained

txtAB gene not detected in DNA prepared from one or more of scabby potato tissue pieces used in isolation; no txtAB+ isolates obtained in this (these) isolation(s)

'txtAB gene not detected in DNA prepared from scabby potato tissue pieces used in isolation, but Spongospora subterranea DNA detected; no txtAB+ isolates obtained

'txtAB gene detected only at a very low level in DNA preparation from some scabby potato tissue pieces used for isolation; no DNA detected in others; few txtAB+ isolates obtained

overview of sampled regions and the types of isolates obtained is presented in Table 2, and all locations are listed in Fig. 1. Ribosomal DNA genotype and presence or absence of genes characteristic of the Streptomyces pathogenicity island (PAI) were determined for a total of 1,471 isolates, derived from 511 independent isolations (tubers). Isolations were made from the full range of lesion types characteristic of CS, including discrete or coalescent superficial, raised, and pitted lesions. Isolates came from numerous potato varieties. Details on potato variety and lesion type for each isolation and the morphological and physiological features of isolates are available from the author. 
Classification of Isolates Into Putative Pathogens or Non-Pathogens

Isolates were first classified into potential pathogens and probable non-pathogens on the basis of whether or not they had $\operatorname{txt} A B$, an operon encoding thaxtomin synthetase, as detected by PCR. Thaxtomin is the only known pathogenicity determinant in Streptomyces, and the presence or absence of $t x t A B$ is $100 \%$ correlated with pathogenicity in more than 100 isolates for which pathogenicity assays have been carried out ((Wanner 2006, 2007a); see also Table 4). The presence of genes for thaxtomin biosynthesis is becoming a widely-used proxy for pathogenicity in Streptomyces (Flores-González et al. 2008; Qu et al. 2008; Wanner 2006, 2007a). About three-quarters (1,074 isolates) of the Streptomyces isolates derived from CS lesions in this study harbored $t x t A B$, and were considered probable pathogens.
Species and Ribotypes Identified

Streptomyces species determinations were based on ribosomal DNA type (ribotype), which is a conventional method for phylogenetically classifying bacteria. Three loop regions of the 1,530 nucleotide $16 \mathrm{~S}$ rRNA vary in sequence in Streptomyces (Wanner 2006). These variable sequence regions are known as $\gamma$ (approximate location nucleotides 168-195), $\alpha$ (approximately nucleotides 970-1,010), and a region between nucleotides 1,430 and 1,440 that has not been characterized as a variable region in bacterial species other than Streptomyces. PCR primers have been designed to distinguish sequences in the variable regions (Wanner 2006). The primer pairs listed in Table 1 were used to type isolates, producing unique patterns of amplicons (ribotypes) depending on the sequence at each variable region. Sequence variable patterns from known pathogenic Streptomyces

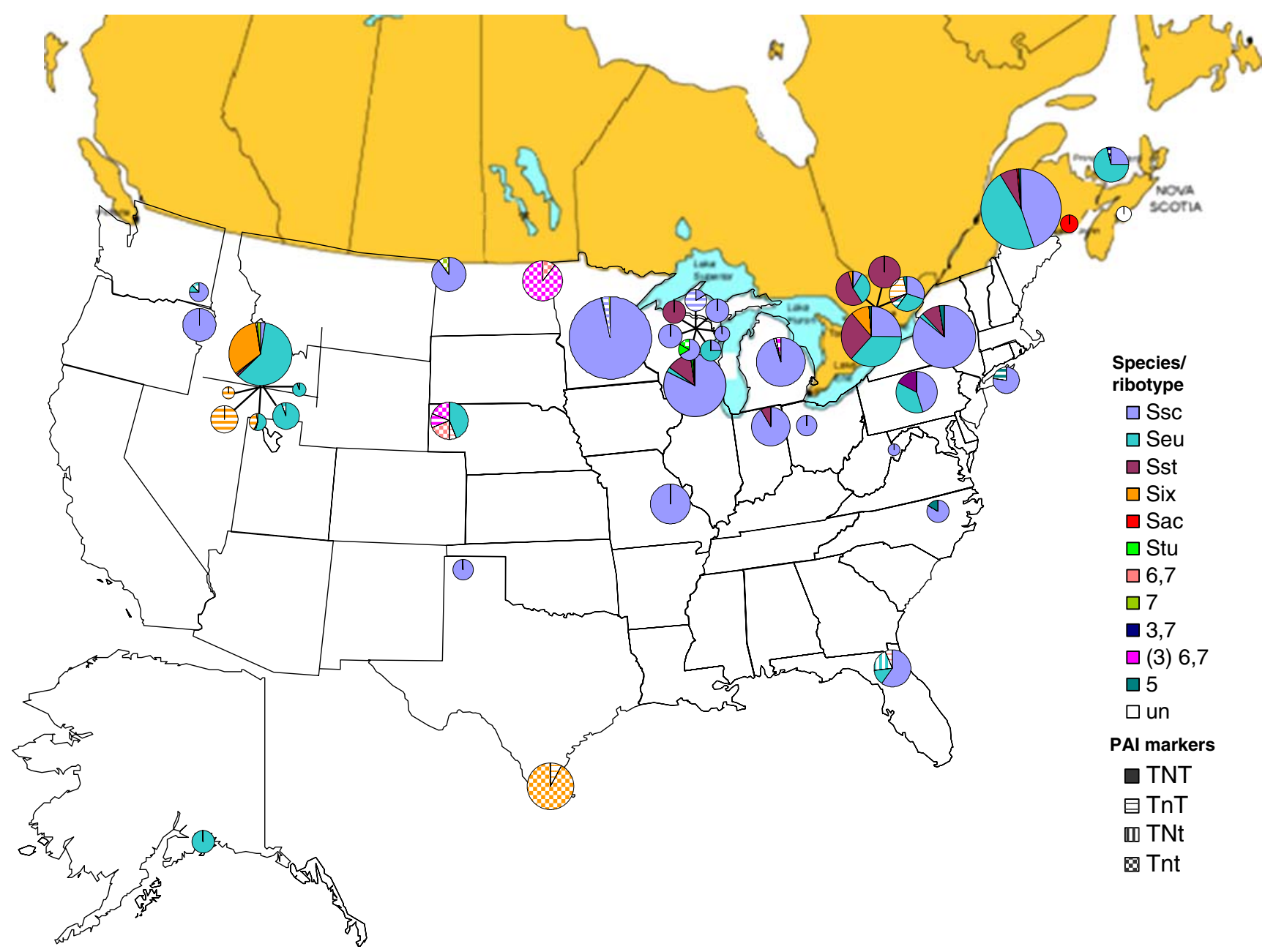

Fig. 2 Map of the presumably pathogenic Streptomyces species associated with CS lesions in North America. Circle diagrams show species/ribotypes in each state or province, with the size of the circle proportional to the number of isolates examined. Species composition and PAI genotypes in multiple nearby field locations in Aberdeen, Idaho, Antigo, Wisconsin, and Alliston, Ontario are also indicated. Species or ribotype indicated in color; PAI types indicated by pattern 


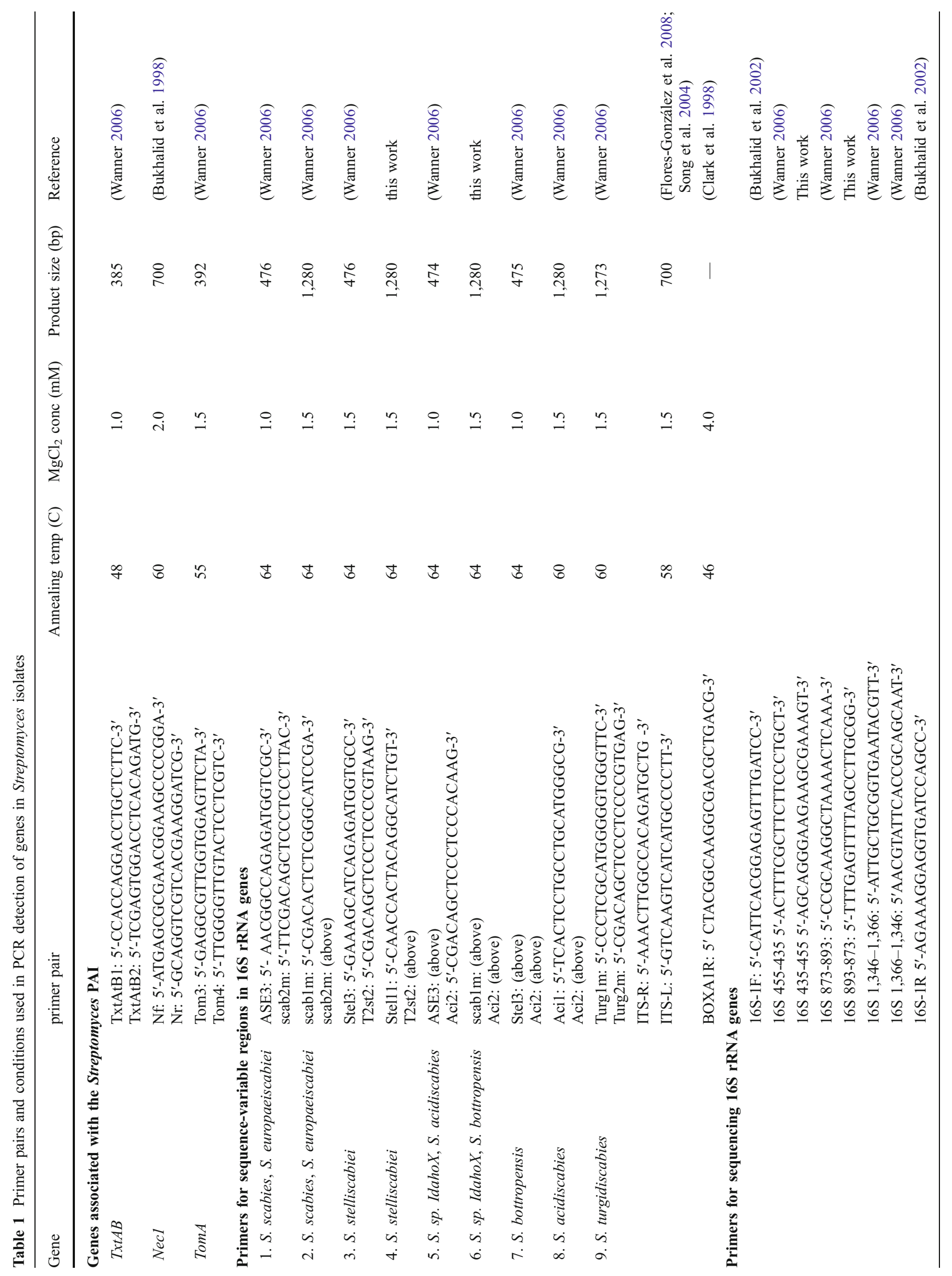


Table 2 Overview of regions and locations surveyed and types of isolates obtained

\begin{tabular}{|c|c|c|c|c|c|c|}
\hline $\begin{array}{l}\text { State or } \\
\text { province }\end{array}$ & $\begin{array}{l}\text { Number of } \\
\text { locations }\end{array}$ & $\begin{array}{l}\text { Number of } \\
\text { isolations }\end{array}$ & $\begin{array}{l}\text { Total isolates } \\
\text { analyzed }\end{array}$ & $\begin{array}{l}\text { Number } t x t A B+ \\
\text { isolates }\end{array}$ & $\begin{array}{l}\text { Total number } \\
\text { ribotypes (species) }\end{array}$ & $\begin{array}{l}\text { Distinct ribotype-PAI } \\
\text { genotype combinations }\end{array}$ \\
\hline AK & 5 & 6 & 7 & 5 & 1 & 1 \\
\hline DE & 1 & 4 & 9 & 0 & 0 & 0 \\
\hline FL & 3 & 17 & 49 & 15 & 3 & 4 \\
\hline ID & 17 & 72 & 168 & 115 & 5 & 8 \\
\hline IN & 2 & 10 & 24 & 24 & 2 & 2 \\
\hline ME & 18 & 47 & 152 & 115 & 4 & 5 \\
\hline MI & 15 & 35 & 92 & 63 & 3 & 4 \\
\hline MN & 3 & 97 & 215 & 188 & 3 & 4 \\
\hline MO & 2 & 11 & 27 & 24 & 1 & 1 \\
\hline NB & 1 & 2 & 12 & 7 & 1 & 1 \\
\hline NC & 2 & 12 & 39 & 7 & 3 & 3 \\
\hline ND & 5 & 17 & 53 & 26 & 4 & 4 \\
\hline $\mathbf{N E}$ & 3 & 6 & 20 & 16 & 4 & 6 \\
\hline NS & 1 & 2 & 7 & 1 & 1 & 1 \\
\hline NY & 13 & 55 & 163 & 127 & 4 & 7 \\
\hline OH & 2 & 5 & 8 & 7 & 1 & 1 \\
\hline ON & 6 & 18 & 103 & 88 & 5 & 8 \\
\hline OR & 2 & 6 & 21 & 21 & 1 & 1 \\
\hline PA & 2 & 13 & 51 & 40 & 3 & 5 \\
\hline $\mathbf{P E}$ & 2 & 5 & 27 & 24 & 3 & 3 \\
\hline $\mathbf{T X}$ & 3 & 8 & 34 & 21 & 2 & 3 \\
\hline WA & 3 & 7 & 10 & 8 & 2 & 3 \\
\hline WI & 24 & 55 & 179 & 131 & 5 & 7 \\
\hline WV & 1 & 1 & 1 & 1 & 1 & 1 \\
\hline total & 135 & 511 & 1,471 & 1,074 & 11 & 28 \\
\hline
\end{tabular}

${ }^{\text {a }}$ among $\operatorname{txt} A B+$ isolates only

species S. scabies, S. europaeiscabiei, S. stelliscabiei, a recently identified strain from Idaho, $S$. acidiscabies and $S$. turgidiscabies have been described (Wanner 2006). The decision matrix used to assign species for North American plant pathogenic Streptomyces isolates based on characteristic sequence types at the $\gamma, \alpha$ and 1,435 variable regions is presented in Table 3, along with the number of isolates identified that were positive for primer combinations. 1,073 txtAB+ isolates - all except one - produced amplicons with at least one of these primer sets, and most could readily be assigned to one of the known pathogenic Streptomyces species.

Since S. scabies (and S. europaeiscabiei) are known to be common pathogenic species, all txtAB+ isolates and nearly all txt $A B$ - isolates were first subjected to PCR with primer pairs 1 or/and 2 (Table 3 ) which amplify characteristic segments of the $16 \mathrm{~S}$ rDNA specific to $S$. scabies and $S$. europaeiscabiei. These two species are nearly identical in 16S rDNA sequence and are not distinguished by PCR targeted to this gene, but they can be distinguished based on sequence differences in the $16 \mathrm{~S}-23 \mathrm{~S}$ ribosomal internal transcribed spacer (ITS). As described by Flores-González et al. (Flores-González et al. 2008), S. scabies has a site for the restriction enzyme Hpy99I, while S. europaeiscabiei does not. Isolates producing amplicons with either set of $S$. scabies/S. europaeiscabiei -specific PCR primers were therefore analyzed for the presence of this restriction fragment length polymorphism in the ribosomal ITS. About half of all isolates $(47 \%)$, and $62 \%$ of the txtAB+ isolates were restricted with $H p y 99 I$, and were therefore assigned to S. scabies, while $17 \%$ of the isolates $(20 \%$ of putative pathogenic isolates) had no site and were assigned to $S$. europaeiscabiei. It should be noted that there is apparently more than one precise ITS/Hpy99I digestion pattern among isolates (see Fig. 3b), but fragment sizes are very close and sequence information would be needed to clarify differences in the ITS.

Isolates not belonging to species $S$. europaeiscabiei or $S$. scabies were analyzed with rDNA primer pairs numbered 3 through 9 in Table 3. This allowed identification of isolates 


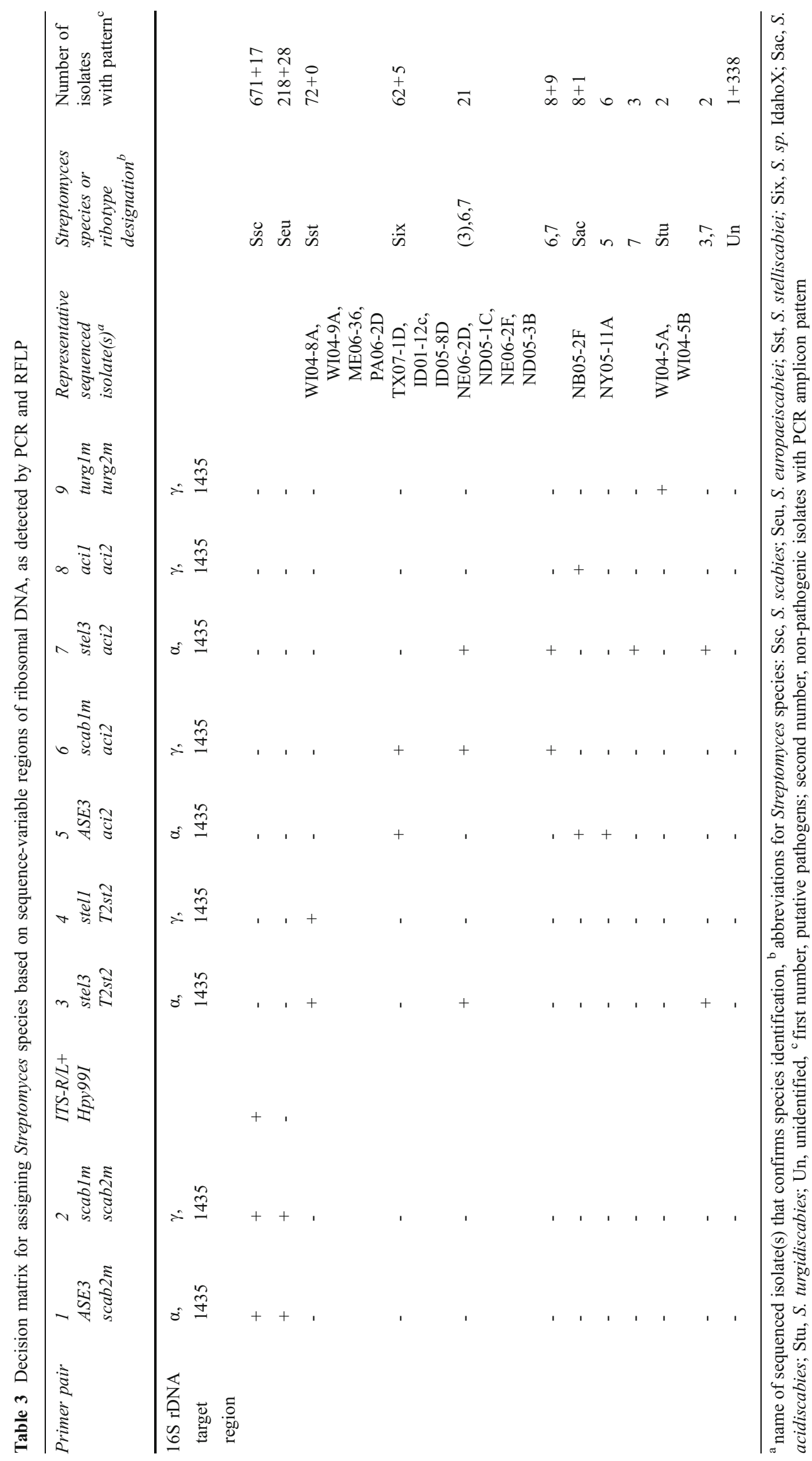



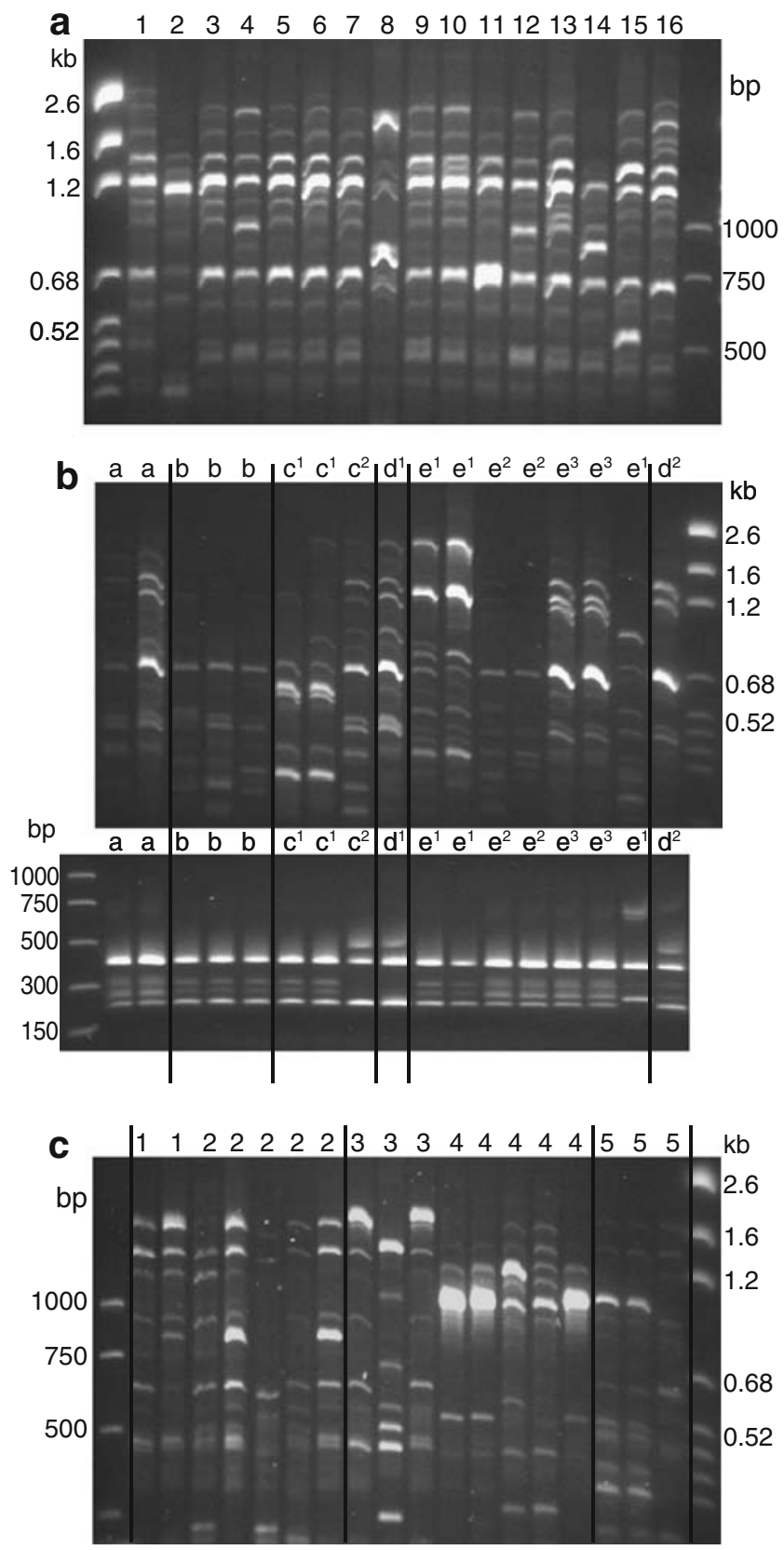

Fig. 3 Repetitive-element (BOX) PCR patterns from Streptomyces isolates. a S. scabies: One common and several additional BOX PCR patterns are seen among $S$. scabies isolates from the eastern half of North America. Lane 1, ATCC $49173^{\mathrm{T}}$; lanes 2 to 16: isolates from separate locations in FL, FL, NC, IN, OH, ME, ME, MI, MI, MI, MN, MN, MO, MO, ND. b S. scabies: Multiple BOX patterns (upper panel) and ITS RFLP patterns (lower panel) in a region (MI), and within single field locations. Isolates from a single location have the same letter and are separated by vertical lines; isolates with the same superscript were recovered from a single isolation. c S. europaeiscabiei: No single frequent BOX pattern was seen among $S$. europaeiscabiei isolates. More than one BOX pattern was found among isolates from individual fields (separated by vertical lines), and among isolates from individual CS lesions (in lanes with same number) belonging to four more species, S. stelliscabiei, S. sp. IdahoX, S. acidiscabies and S. turgidiscabies. This is the first report of S. turgidiscabies in North America. A $16 \mathrm{~S}$ rDNA gene was cloned and sequenced from one or more representatives of each of these species, confirming that the entire sequence of $16 \mathrm{~S}$ rRNA genes from these isolates matched the identification made using the primer sets (Table 3). Together, four species accounted for $95 \%$ of txtAB+ isolates: $S$. scabies, $S$. europaeiscabiei, S. stelliscabiei, and S. sp. IdahoX. The other two previously described pathogenic species identified by ribotype, S. acidiscabies and S. turgidiscabies, accounted for less than $1 \%$ of pathogenic isolates.

About $5 \%$ of isolates showed unique combinations of PCR amplicons that did not correspond to one of the above six known plant-pathogenic Streptomyces species. Several isolates from North Dakota and Nebraska, and single isolates from Minnesota and Florida produced amplicons with primer pairs 6 and 7, consistent with the 16S rDNA sequence of $S$. bottropensis. Two isolates had a new combination of known $\gamma, \alpha$ and 1,435 sequences, producing PCR amplicons with primer pairs 3 and 7 , and a small number of isolates showed an amplicon only with primer pair 7 , or only with primer pair 5. In these cases, the sequence at the $\gamma$ variable region is undetermined with the present sets of primers. No 16S rDNA sequence has been determined for a primer pair 3,7- or 7positive isolate, but cloning and sequencing of an isolate from the primer pair 5-positive group indicates that it is closely related to $S$. achromogenes subspecies tomaymyceticus, and several non-pathogenic species or strains.

One relatively frequent PCR pattern is hard to explain. More than 20 isolates from several locations in Nebraska and North Dakota and a location in Michigan consistently produced amplicons with primer pairs 3,6 and 7. This would imply two different sequences at the $\alpha$ variable region. Streptomyces species typically have six copies of the ribosomal gene repeat and there are examples of sequence polymorphisms among the rDNA gene copies in a few bacterial species (Klappenbach et al. 2001), but this is infrequent and was not the case for the three published Streptomyces genomes (Bentley et al. 2002; Ikeda et al. 2003; Ohnishi et al. 2008). A 16S rDNA gene from five isolates with this ribotype was sequenced. Three were $100 \%$ identical to S. bottropensis (GenBank accession D63868) over the entire length, and one had a single mismatch. The fifth (3), 6, 7 isolate grouped with $S$. clavifer and $S$. mutomycini, and was most closely related to two non-pathogenic isolates also derived from potato CS lesions from the same geographic region, ND04-1H (GenBank accession EU080958) and ND04-6F (EU080960). In all five cases, the sequence data obtained correspond to ribotype 6,7 . No cloned $16 \mathrm{~S}$ rDNA was obtained showing a sequence expected for primer pair 3. However, increasing the annealing temperature to 65 during PCR with primer 
pair 3 resulted in clearly weaker amplicons from the ribotype (3), 6, 7 isolates than from typical ribotype 3, 4 (S. stelliscabiei) isolates, suggesting that (3), 6, 7 isolates might have fewer copies of a ribotype $316 \mathrm{~S}$ rDNA gene than the ribotype 7 version. To resolve this, additional cloning and sequencing is needed.

Geographic Distribution: Geography is a Partial Predictor of Prevalent Pathogenic Species

The most common CS-associated Streptomyces species were $S$. scabies and $S$. europaeiscabiei. However they were differently distributed, with $S$. europaeiscabiei predominating in Alaska, Idaho, Ontario and Prince Edward Island and $S$. scabies predominating in Washington, Oregon, Minnesota, Missouri, Wisconsin, Indiana, Michigan and New York (Fig. 1). The two species were found in about equal proportions in Maine and Pennsylvania (Fig. 1). Other species were prevalent in some locations. S. acidiscabies was the most common species observed in a location in New Brunswick, while most other regions had more than one abundant species or ribotype. Unique ribotype profiles were seen in the western Midwest. For example, in Nebraska and North Dakota, S. europaeiscabiei and the $S$. bottropensis-like 6, 7 and (3), 6, 7 ribotypes were similarly abundant. $S$. stelliscabiei was found sporadically in many regions, and $S$. $s p$. Idaho $X$ was frequent in the west, but found sporadically in other regions. The numbers of isolates of each species or ribotype in each location are presented in Fig. 1.

BOX PCR Reveals Underlying Heterogeneity Within Single Species, especially S. europaeiscabiei

To determine whether isolates belonging to a species according to ribotype were genetically similar across the continent, genomic organization was examined in $350 \mathrm{~S}$. scabies and $S$. europaeiscabiei isolates from various locations using repetitive element PCR based on the BOXA1R primer (Clark et al. 1998; Sadowsky et al. 1996). There was a very frequent BOX PCR pattern among $S$. scabies isolates, especially in the Midwestern part of the continent (Fig. 3a lanes 3, 5-7; several others are very similar). However, many additional patterns were found. Furthermore, in S. scabies isolates from five fields in Michigan, different BOX patterns were seen in different field locations, within a single field, and among isolates from a single lesion (Fig. 2b, upper panel). Similar results were obtained in Maine and at least five distinct patterns were seen in S. scabies isolates from a single field in Indiana. Therefore, there are apparently genetic differences within species. Further support for differences in the genetic make-up of isolates sharing a 16S rDNA ribotype is provided by variation in RFLPs in the ribosomal intergenic transcribed spacer (ITS); examples are shown in the lower panel of Fig. 2b. Core genomic organization was more variable among $S$. europaeiscabiei isolates than among S. scabies isolates; no single frequent pattern was identifiable (Fig. 2c). Again, more than one pattern was found among isolates from a single field and from a single CS lesion (Fig. 2c).

Presence or Absence of Additional Markers of the Streptomyces PAI

All txtAB-positive isolates, and nearly all txtAB- isolates, were characterized for the presence or absence of two additional genes characteristic of the Streptomyces PAI, the necl gene and the tomA gene. As shown in Fig. 1, the large majority $(87 \%)$ of txtAB+ isolates also harbored the nec 1 and tomA genes. This is represented as PAI type TNT in Fig. 1. Seven of the ten ribotypes (species) included isolates of the TNT type. However, isolates missing one or both of these genes were found among all Streptomyces species/ ribotypes, and isolates from $S$. sp. IdahoX and ribotypes 6/7, (3)/6/7 and 7 typically were missing one or both of these genes. Isolates of the latter ribotypes had PAI types $\mathrm{TnT}$ and Tnt. Specific combinations of species/ribotype and PAI type were frequently typical of a single field location.

Not all txtAB- isolates were screened for the presence of the tomA and necl genes, but among those genotyped, at least 77 isolates had one or both of these genes (Fig. 1, lighter-shaded column blocks). Since these isolates all originated from CS lesions on potato skins, this suggests that genes characteristic of the PAI are frequently available and independently mobile in the potato tuber environment.

\section{Pathogenicity of Different Species and PAI Genotypes}

Sixty-three isolates, representing at least seven species/ ribotypes and various combinations of the three PAIassociated genes $t x t A B, n e c l$ and tomA, were tested for pathogenicity in radish or/and potato (Table 4). All 44 txtAB+ isolates tested were pathogenic. One txtAB- isolate produced mild lesions (tested on radish), while the other 18 txt $A B$ isolates were non-pathogens. Pathogenic txtAB+ isolates belonged to six species/ribotypes (S. scabies, S. europaeiscabiei, S. stelliscabiei, and S. sp. IdahoX, ribotype 5 and ribotype (3),6, 7). Several txtAB+ isolates lacking the necl gene or/and the tomA gene were fully pathogenic, and capable of inducing all lesion types on susceptible potato cultivars or/and on radishes (Table 4). No obvious effect on virulence was noticed; however, this pathogenicity test was not designed to compare virulence of different isolates, since both pathogen inoculum density and plant cultivar susceptibility are critical co-variables that would need to be specifically considered in virulence testing. 
Table 4 Pathogenicity test results for Streptomyces isolates belonging to different species and PAI genotypes
${ }^{a}$ Isolates from a single state and year that are displayed in different colors came from different field locations, ${ }^{\mathrm{b}}$ Species or ribotype as determined according to Table 3; Un, not determined, ${ }^{\mathrm{c}}$ PAI genotype designations: first $\mathrm{T} / \mathrm{t}$, presence/ absence of txtAB; second $\mathrm{N} / \mathrm{n}$, presence/absence of necl; third $\mathrm{T} / \mathrm{t}$, presence/absence of tom $A$, ${ }^{\mathrm{d}}$ pathogenicity test results on radish or potato

\begin{tabular}{|c|c|c|c|c|}
\hline isolate $^{a}$ & $\begin{array}{l}\text { species/ } \\
\text { ribotype }\end{array}$ & $\begin{array}{c}\text { PAl } \\
\text { genotype }\end{array}$ & $\begin{array}{c}\text { path } \\
\text { potato }\end{array}$ & $\begin{array}{c}\text { path } \\
\text { radish }^{\mathrm{d}}\end{array}$ \\
\hline NY-05-11A & 5 & TnT & + & \\
\hline ND-05-03B & $3 / 6 / 7$ & Tnt & + & \\
\hline AK-02-2a & europaeiscabiei & TNT & & + \\
\hline AK-02-3a & europaeiscabiei & TNT & & + \\
\hline ID-01-13c & europaeiscabiei & TNT & + & + \\
\hline ID-01-16c & europaeiscabiei & TNT & + & + \\
\hline ID-01-8a & europaeiscabiei & TNT & + & + \\
\hline ID-02-14 & europaeiscabiei & TNT & & + \\
\hline ID-02-12 & europaeiscabiei & $\mathrm{TNt}$ & + & + \\
\hline MI-02-2 & europaeiscabiei & Tnt & + & + \\
\hline ID-05-11E & IdahoX & $T n^{*} T$ & + & \\
\hline ID-01-12c & IdahoX & TnT & + & + \\
\hline ID-01-6.2a & IdahoX & TnT & + & + \\
\hline ID-03-1A & IdahoX & TnT & & + \\
\hline ID-03-2a & IdahoX & TnT & & + \\
\hline ID-03-3a & IdahoX & TnT & + & + \\
\hline ID-02-15 & scabies & TNT & & + \\
\hline ID-02-16 & scabies & TNT & & + \\
\hline MI-02-2B & scabies & TNT & & + \\
\hline $\mathrm{Ml}-02-3 \mathrm{c}$ & scabies & TNT & & + \\
\hline MI-02-3D & scabies & TNT & & + \\
\hline MI-02-6A & scabies & TNT & & + \\
\hline MN-04-03 & scabies & TNT & + & \\
\hline NY-02-2a & scabies & TNT & & + \\
\hline $\mathrm{OH}-01-12 \mathrm{c}$ & scabies & TNT & + & + \\
\hline $\mathrm{OH}-01-5.2$ & scabies & TNT & & + \\
\hline $\mathrm{OH}-01-5 \mathrm{a}$ & scabies & TNT & + & + \\
\hline $\mathrm{OH}-01-5 \mathrm{~d}$ & scabies & TNT & & + \\
\hline $\mathrm{OH}-01-6.2 \mathrm{a}$ & scabies & TNT & + & + \\
\hline $\mathrm{OH}-01-6 \mathrm{a}$ & scabies & TNT & + & + \\
\hline $\mathrm{OH}-03-1 \mathrm{a}$ & scabies & TNT & & + \\
\hline WI-03-1b & scabies & TNT & & + \\
\hline WI-03-3a & scabies & TNT & & + \\
\hline WI-03-4c & scabies & tNT & & - \\
\hline WI-03-5a & scabies & TNT & & + \\
\hline WI-03-1a & scabies & TnT & & + \\
\hline ID-02-6 & stelliscabiei & TNT & & + \\
\hline IN-05-2A & stelliscabiei & TNT & + & \\
\hline NY-02-18 & stelliscabiei & TNT & & + \\
\hline NY-02-1a & stelliscabiei & TNT & & + \\
\hline NY-02-1b & stelliscabiei & TNT & & + \\
\hline NY-02-1c & stelliscabiei & TNT & & + \\
\hline NY-02-3a & stelliscabiei & TNT & + & + \\
\hline$N Y-02-3 c$ & stelliscabiei & TNT & & + \\
\hline NY-05-08A & stelliscabiei & TNT & + & \\
\hline ID-01-9d & Un & tn & - & - \\
\hline
\end{tabular}


Table 4 (continued)

\begin{tabular}{|c|c|c|c|c|}
\hline isolate $^{a}$ & $\begin{array}{l}\text { species/ } \\
\text { ribotype }^{b}\end{array}$ & $\begin{array}{c}\text { PAl } \\
\text { genotype }\end{array}$ & $\begin{array}{c}\text { path } \\
\text { potato }^{d}\end{array}$ & $\begin{array}{l}\text { path } \\
\text { radish }^{d}\end{array}$ \\
\hline AK-02-4a & Un & tnt & & - \\
\hline ID-01-11a & Un & tnt & - & - \\
\hline ID-01-11c & Un & tnt & - & - \\
\hline ID-01-14c & Un & tnt & - & - \\
\hline ID-01-14d & Un & tnt & & - \\
\hline ID-01-15b & Un & tnt & - & - \\
\hline ID-01-15d & Un & tnt & - & - \\
\hline ID-02-13 & Un & tnt & & - \\
\hline ID-03-1B & Un & tnt & & $+/-$ \\
\hline ID-03-2b & Un & tnt & & - \\
\hline MI-02-2A & Un & tnt & & - \\
\hline MI-02-5a & Un & tnt & & - \\
\hline MI-02-7a & Un & tnt & & - \\
\hline $\mathrm{OH}-01-11 \mathrm{c}$ & Un & tnt & - & - \\
\hline WI-03-4a & Un & tnt & & - \\
\hline WI-03-6b & 5 & tnt & & - \\
\hline WI-03-5b & 3,7 & tnt & & - \\
\hline
\end{tabular}

Locations from Which No or very Few txtAB+ Isolates were Obtained

In a few cases, multiple attempted isolations from several individual potato tubers displaying typical CS-like lesions yielded few or no txtAB+ isolates. In most of these cases, very few Streptomyces colonies were obtained on initial isolation plates. Notable failed attempts to isolate pathogenic strains were from locations in Delaware, Florida, North Dakota, Wisconsin, New York, North Carolina, and Maine (Fig. 1). For several of these, DNA extracts from tuber lesion pieces were examined by quantitative PCR using primers specific for the txtAB operon (Qu et al. 2008), for Spongospora subterranea (the powdery scab pathogen) (Qu et al. 2006), and for a potato cytochrome oxidase gene (quantitative PCR data kindly produced by Dr. Xinshun Qu, Pennsylvania State University). The potato gene was easily detected, but in most cases, the txtAB gene, indicating presence of any pathogenic Streptomyces species, was not detected or detected at very low levels. This corresponds to the difficulty in isolating pathogenic Streptomyces. In only one case was the powdery scab pathogen detected in the tissue piece. The cause of scabby lesions in cases where neither txtAB nor $S$. subterranea could be detected is unknown. A pair of primers specific to Rhizoctonia solani AG3 (A. K. Lees 2002) was also tried, but did not produce diagnostic PCR fragments from these lesion tissues.

\section{Discussion}

For more than a hundred years, Streptomyces scabies has been recognized as the cause of common scab on potato as well as other underground root and tuber crops (Loria et al. 2006). With the advent of molecular genetic characterization of CS-causing species, it became apparent that Streptomyces scabies was a complex of species (BouchekMechiche et al. 2000; Bukhalid et al. 2002; Doering-Saad et al. 1992; Healy and Lambert 1991; Takeuchi et al. 1996). Morphological, physiological and molecular evidence currently supports the designation of about ten CS-causing species known from one or more geographic locations around the world. Knowledge of the frequency and distribution of these species is limited, since the characterized collections of pathogenic Streptomyces have been small, and have represented few geographic areas (BouchekMechiche et al. 1998, 2000; Flores-González et al. 2008; Kreuze et al. 1999; Lindholm et al. 1997; Park et al. 2003a; Song et al. 2004; Takeuchi et al. 1996; Wanner 2006). This is the most extensive study of plant pathogenic Streptomyces to date, including more than 1,400 isolates obtained from 135 locations representing much of the primary potato production region of North America. On average, 10.9 isolates were obtained per field location, and 2.9 isolates were examined per isolation (CS lesion). Genetic variation in the roughly three quarters of isolates presumed to be pathogenic on the 
basis of the presence of genes for biosynthesis of the pathogenicity determinant thaxtomin $(t x t A B+)$ was characterized in several ways. Species affiliation was identified, and the extent of variation within the core genome of numerous txtAB+S. scabies and S. europaeiscabiei isolates was examined using repetitive sequence element PCR. The presence or absence of genes associated with the pathogenicity region of $S$. scabies and $S$. turgidiscabies was established using PCR.

Recently, sequence information has provided a convenient basis for identifying species. In bacteria, the most common sequence used for classification purposes is the $16 \mathrm{~S}$ rRNA gene. Although this gene is highly conserved due to constraints imposed by proper folding and assembly into ribosomes, a few short variable loops have provided adequate variation for classification to genus, and frequently, to species. These sequence-variable regions have been useful in Streptomyces taxonomy. Diagnostic variable regions in this gene have been used here to classify 1,033 of a total of 1,074 potentially pathogenic isolates from 24 US states and Canadian provinces into six Streptomyces

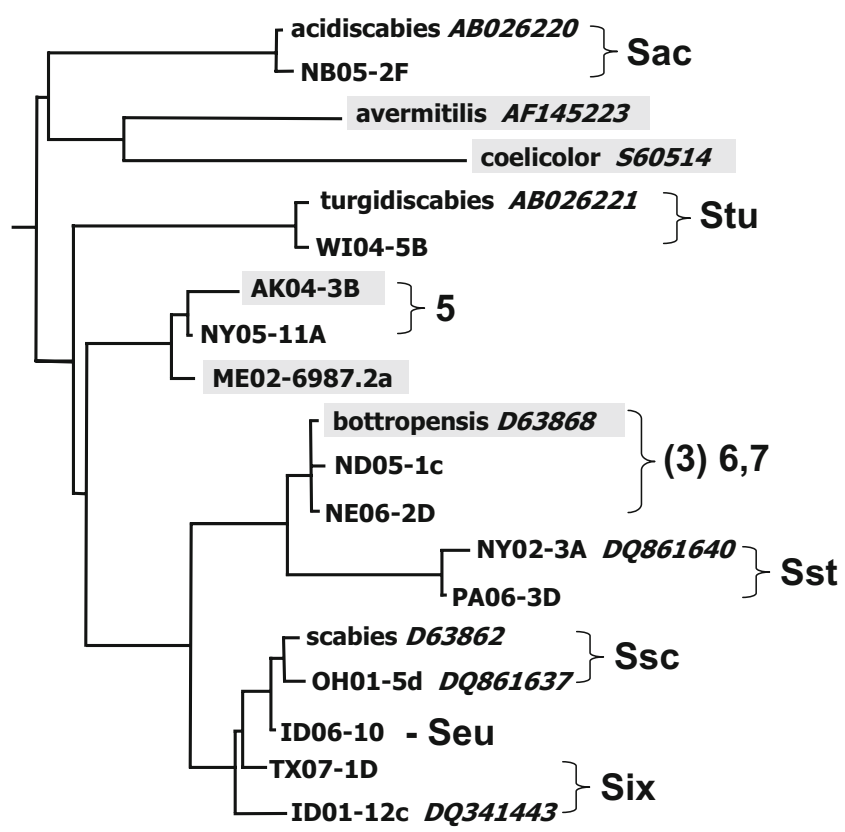

Fig. 4 Phylogenetic relationships between Streptomyces species found harboring the $t x t A B$ operon in North America. The neighborjoining tree (Saitou and Nei 1987) with branch lengths is based on a ClustalW alignment of the complete 1531 nucleotide sequences of $16 \mathrm{~S}$ rRNA genes (alignment done at the Kyoto University Bioinformatics website, http://align.genome.jp/). Sequenced isolates from this project representing S. scabies, S. europaeiscabiei, S. acidiscabies, $S$. $s p$. IdahoX, S. turgidiscabies, S. bottropensis, and other combinations of $\gamma, \alpha$ and 1435 variable regions (ribotypes) were used. Species $S$. scabies (ATCC 49173; D63862), S. stelliscabiei (ATCC700248; AB026221), S. bottropensis (D63868), S. coelicolor (X60514), and S. avermitilis (AF145223) are included as reference points. Nonpathogenic species are shaded species. All of these species have previously been associated with CS in Europe or North America, although this is the first report of $S$. turgidiscabies in North America. In this relatively large North American survey, all but 51 of 1,074 isolates containing the txtAB operon (that is, 95\%) could be assigned to four Streptomyces species. These four species, S. scabies, S. stelliscabiei, S. europaeiscabiei, and $S$. $s p$. Idaho $\mathrm{X}$, are closely-related in 16S rRNA sequence (Fig. 4).

The mechanism of spread of pathogenicity by horizontal transfer of chromosomal or plasmid-borne DNA regions encoding groups of pathogenicity genes (a PAI) which has been demonstrated for Streptomyces (Kers et al. 2005; Loria et al. 2006) brings up the possibility of the continuous appearance of new pathogenic species, especially in a genus as large and ubiquitous in soils as Streptomyces. A small percentage of txtAB+ isolates (42 isolates, about 4\%) did not fall into one of six previously known scab-causing Streptomyces species according to $16 \mathrm{~S}$ rDNA ribotype. Among these, five different ribotypes were found. Two fairly large and widespread groups comprised of 29 isolates share a ribotype with $S$. bottropensis, a species closely related to the four predominant CS species, S. scabies, $S$. europaeiscabiei, S. sp. IdahoX and S. stelliscabiei, but most closely related to S. stelliscabiei (Fig. 4). This finding substantiates an earlier report that $S$. bottropensis may include pathogenic strains (Bukhalid et al. 2002). The $16 \mathrm{~S}$ rDNA gene from an isolate of a third ribotype was sequenced; it is most closely related to two nonpathogenic isolates also derived from potato CS lesions, ME02-6987.2a (GenBank accession EU080949.1) and AK03-4B (EU080939.1), and to S. achromogenes subspecies tomaymyceticus. This ribotype is, like $S$. acidiscabies and $S$. turgidiscabies, less closely-related to the other CSassociated species (Fig. 4). No 16S gene was sequenced from the remaining two ribotypes found here, represented by only five isolates. A striking feature of isolates of all five of these ribotypes is that they generally lacked the necl gene; many also lacked the tom $A$ gene. Only one $t x t A B+$ isolate produced no product with the group of primers to 16S rDNA used here. Three species reported to cause CS in Korea (Park et al. 2003a) were not identified in the North American collection. Isolates harboring the $t x t A B$ gene and belonging to six different species or ribotypes were tested for pathogenicity. All were pathogenic, whether or not they also harbored the necl or the tomA genes, two additional genes characteristic of the Streptomyces PAI.

Although most isolates recovered from scabby tuber lesions contained genes for biosynthesis of the phytotoxin thaxtomin, about a quarter did not. The occurrence of nonpathogenic S. scabies, S. acidiscabies, and S. turgidiscabies has been regularly reported (Faucher et al. 1992; Lindholm et al. 1997; Wanner 2006), and a disproportionate number 
of non-pathogenic isolates was previously reported from tolerant potato varieties and from less severe lesions or other types of blemish (Wanner 2007a). In the present collection of isolates, the proportion of txtAB+ Streptomyces isolates recovered differed between species/ribotypes, ranging from $100 \%$ of $S$. stelliscabiei isolates and $97 \%$ of $S$. scabies isolates down to $56 \%$ of ribotype (3) 6,7 and 6,7 isolates. It was also difficult to obtain txtAB+ isolates from some sampling sites, even though tubers had fairly typical CS lesions. The absence of txtAB+ isolates from these locations needs further investigation.

Since the Streptomyces PAI is thought to be horizontally transferred as a unit, and previous studies have indicated high conservation in gene sequence for the PAI-associated necl gene (Bukhalid et al. 1998), it could be expected that txtAB+ isolates and species would harbor all known PAI genes. On the other hand, numerous examples of txtAB+ isolates missing the necl gene have been reported (FloresGonzález et al. 2008; Kreuze et al. 1999; Wanner 2006). With an estimated size of more than $500 \mathrm{kbp}$, the Streptomyces PAI is exceptionally large for a PAI, and the necl and txtAB genes are reported to be located at opposite ends of this long region (Kers et al. 2005). A saponinaselike gene (tomA), also characteristic of the PAI, apparently lies outside of necl, more distant from txtAB. These two genes were traced in the isolates. Most $t x t A B+$ isolates of species S. scabies, S. europaeiscabiei and S. stelliscabiei had both genes from the other "end" of the PAI, although isolates harboring most combinations of the three PAI genes (txtAB, tomA and necl) were found. However, some species typically had a different composition of PAI genes. As previously reported (Wanner 2007b) $S$. $s p$. Idaho X nearly always had tomA but not necl. The two $S$. bottropensis-like groups typically lacked both tomA and necl. TomA and neclwere also frequently found in $t x t A B$ - isolates, as shown in Fig. 1. This observation suggests that non-pathogenic Streptomyces species inhabiting the plant (or potato) rhizosphere might serve as a source or reservoir for some or all of these pathogenicity-associated genes.

There were general regional patterns in Streptomyces species prevalence. The most abundant species found was $S$. scabies, especially in the Midwestern USA. S. europaeiscabiei, which is predominant in Europe, was unexpectedly common in North America; it was the predominant species in much of the west, and a co-dominant species in Ontario and the northeastern USA. S. stelliscabiei was not a predominant species in any region, although it predominated in some field locations. $S$. $s p$. Idaho $\mathrm{X}$ was co-dominant in Idaho and Texas, where it was the major or only species found in some fields. S. acidiscabies, which has previously been described in the northeastern USA, was found rarely; a single isolate from northern Maine and several isolates from a single location in New Brunswick were the only examples. This observation corresponds to reports that $S$. acidiscabies is not persistent in soil (Lambert and Loria 1989b; Lambert et al. 2006). S. turgidiscabies was also very infrequent; $S$. acidiscabies and $S$. turgidiscabies may be ephemeral causes of CS in North America. These two species are also the most distantly related to the four predominant CS-associated species (Fig. 4), suggesting that either their association with potatoes is weaker, or they are less able to acquire and maintain the Streptomyces PAI.

Overlying regional species patterns, individual field locations frequently yielded only one species. However, field locations in near geographic proximity were often characterized by different pathogen species (Figs. 1 and 2). Fields in Alliston, ON, Aberdeen, ID, Aroostook County, ME, Antigo, WI, and Ithaca, NY all showed this varied species composition, along with many examples of variant PAI genotypes. Since these were the most intensivelysampled areas, a mosaic pattern of species and PAI genotypes may be the rule more than the exception.

Common scab is a cosmopolitan disease, affecting potatoes wherever they are grown, and Streptomyces species causing the disease have been described from around the world. Bacterial pathogens causing cosmopolitan diseases often have a clonal population structure, as they result from clonal expansion in the host of one or a few closely related pathogenic strains. This is particularly the case for diseases spread by human trade, travel, and commerce, a situation characterizing the potato host of common scab. Some locations with large numbers of studied isolates were very homogeneous in both species and PAI genotype. This was notably the case in Minnesota, and relative homogeneity also characterized locations in Missouri, Oregon and Indiana. However, multiple BOX PCR patterns were observed in isolates of a single species from a single location, and even from a single lesion. Many locations harbored more than one species, and there were isolates from a single lesion belonging to two species. Valkonen's group in Finland has also reported that more than one species can co-inhabit single CS lesions (Lehtonen et al. 2004). From these observations, we can conclusively say that pathogenic Streptomyces in single fields and even single lesions are not clonal.

Some interesting questions posed by the results are, why is pathogenicity mostly limited to a few closely related species, with infrequent (and possibly transient) appearances of a few other, more distantly related species? Does this have more to do with a mutual preference of these species for potatoes, or potatoes for these species, or is there a reason why the Streptomyces PAI, or parts of it, can only be stably transferred or maintained in certain species? The presence of multiple species, core genome types, and PAI genotypes in the same field and even the same lesion, and the presence of non-pathogenic strains harboring bits of the PAI in CS lesions suggests a dynamic situation of continual loss, gain 
and exchange of PAI elements among closely-related species. It will be interesting to see if the limited species partnership is driven by the plant host, or is a function of maintenance of the PAI in a limited phylogenetic sector of the species Streptomyces. The answers to these questions about the ecological interaction between potatoes and the pathogen may provide new ideas for controlling CS.

In summary, of a total of 1,471 isolates obtained from common scab lesions on potato tubers in North America, $73 \%$ ( 1,074 isolates) were presumed to be pathogenic because they harbored genes for biosynthesis of thaxtomin, the only known pathogenicity determinant in Streptomyces. Virtually all presumably pathogenic isolates could be assigned to species according to features of the 16S rDNA sequence in combination with the ribosomal intergenic spacer sequence. Pathogenic Streptomyces isolates belong to at least six species, all of which have been described as pathogens previously. This is the first report of pathogenic $S$. turgidiscabies and $S$. bottropensis in North America. Common scab-causing species are found in a patchy pattern on both local and larger geographic scales. Four closelyrelated species account for the majority of isolates, and they frequently, but not always, carry one or more genes characteristic of the Streptomyces PAI. Overall, 12 ribotypes, and a total of 28 ribotype-PAI genotype combinations were identified. Less closely related streptomycetes isolated from CS lesions occasionally carry one or more genes characteristic of the Streptomyces PAI. This large research collection is the most extensive survey to date of the distribution of potential CS-causing Streptomyces species, and is a resource for population biology studies on potato-associated streptomycetes, and for tracing the evolutionary history and spread of CS-associated Streptomyces in North America.

Acknowledgments Thanks to Dr. Xinshun Qu for the quantitative PCR analysis of the presence of txtAB, Spongospora subterranea, and potato cytochrome oxidase DNA in potato CS lesion tissue. Technical assistance by Stephanie Ray is gratefully acknowledged. This research was supported by USDA-ARS CRIS project number 1275-21220-223 0OD.

\section{References}

Bentley, S.D., K.F. Chater, A.M. Cerdeno-Tarraga, G.L. Challis, N.R. Thomson, K.D. James, D.E. Harris, M.A. Quail, H. Kieser, D. Harper, A. Bateman, S. Brown, G. Chandra, C.W. Chen, M. Collins, A. Cronin, A. Fraser, A. Goble, J. Hidalgo, T. Hornsby, S. Howarth, C.H. Huang, T. Kieser, L. Larke, L. Murphy, K. Oliver, S. O'Neil, E. Rabbinowitsch, M.A. Rajandream, K. Rutherford, S. Rutter, K. Seeger, D. Saunders, S. Sharp, R. Squares, S. Squares, K. Taylor, T. Warren, A. Wietzorrek, J. Woodward, B.G. Barrell, J. Parkhill, and D.A. Hopwood. 2002. Complete genome sequence of the model actinomycete Streptomyces coelicolor A3(2). Nature 417: 141-147.
Bouchek-Mechiche, K., C. Guerin, B. Jouan, and L. Gardan. 1998. Streptomyces species isolated from potato scabs in France: numerical analysis of "Biotype-100" carbon source assimilation data. Research in Microbiology 149: 653-663.

Bouchek-Mechiche, K., L. Gardan, P. Normand, and B. Jouan. 2000. DNA relatedness among strains of Streptomyces pathogenic to potato in France: description of three new species, $S$. europaeiscabiei sp. nov. and S. stelliscabiei sp. nov. associated with common scab, and S. reticuliscabiei sp. nov. associated with netted scab. International Journal of Systematic and Evolutionary Microbiology 50: 91-99.

Bukhalid, R.A., S.Y. Chung, and R. Loria. 1998. necl, a gene conferring a necrogenic phenotype, is conserved in plantpathogenic Streptomyces spp. and linked to a transposase pseudogene. Molecular Plant-Microbe Interaction 11: 960-967.

Bukhalid, R.A., T. Takeuchi, D. Labeda, and R. Loria. 2002. Horizontal transfer of the plant virulence gene, necl, and flanking sequences among genetically distinct Streptomyces strains in the Diastatochromogenes cluster. Applied and Environmental Microbiology 68: 738-744.

Clark, C.A., A. Chen, N. Ward-Rainey, and G.S. Pettis. 1998. Diversity within Streptomyces ipomoeae based on inhibitory interactions, REP-PCR, and plasmid profiles. Phytopathology 88: 1179-1186.

Doering-Saad, C., P. Kampfer, S. Manulis, G. Kritzman, J. Schneider, J. Zakrzewska-Czerwinska, H. Schrempf, and I. Barash. 1992. Diversity among Streptomyces strains causing potato scab. Applied and Environmental Microbiology 58: 3932-3940.

Faucher, E., T. Savard, and C. Beaulieu. 1992. Characterization of actinomycetes isolated from common scab lesions on potato tubers. Canadian Journal of Plant Pathology 14: 197-202.

Flores-González, R., I. Velasco, and F. Montes. 2008. Detection and characterization of Streptomyces causing potato common scab in Western Europe. Plant Pathology 57: 162-169.

Goth, R.W., K.G. Haynes, and D.R. Wilson. 1993. Evaluation and characterization of advanced potato breeding clones for resistance to scab by cluster analysis. Plant Disease 77: 911-914.

Goyer, C., B. Otrysko, and C. Beaulieu. 1996. Taxonomic studies on streptomycetes causing potato common scab: a review. Canadian Journal of Plant Pathology 18: 107-113.

Haynes, K.G., R.W. Goth, and R.J. Young. 1997. Genotype X environment interactions for resistance to common scab in tetraploid potato. Crop Science 37: 1163-1167.

Healy, F.G., and D.H. Lambert. 1991. Relationships among Streptomyces spp. causing potato scab. International Journal of Systematic Bacteriology 41: 479-482.

Hill, J., and G. Lazarovits. 2005. A mail survey of growers to estimate potato common scab prevalence and economic loss in Canada. Canadian Journal of Plant Pathology 27: 46-52.

Hiltunen, L.H., A. Weckman, A. Ylhäinen, H. Rita, E. Richter, and J. P.T. Valkonen. 2005. Responses of potato cultivars to the common scab pathogens, Streptomyces scabies and S. turgidiscabies. Annals of Applied Biology 146: 395-403.

Hopwood, D.A. 2006. Soil to genomics: the streptomyces chromosome. Annual Review of Genetics 40: 1-23. doi:10.1146/annurev. genet.40.110405.090639.

Ikeda, H., J. Ishikawa, A. Hanamoto, M. Shinose, H. Kikuchi, T. Shiba, Y. Sakaki, M. Hattori, and S. Omura. 2003. Complete genome sequence and comparative analysis of the industrial microorganism Streptomyces avermitilis. Nature Biotechnology 21: 526-531.

Janssen, P.H. 2006. Identifying the dominant soil bacterial taxa in libraries of 16S rRNA and 16S rRNA genes. Applied Environmental Microbiology 72: 1719-1728.

Kers, J., K. Cameron, M. Joshi, R. Bukhalid, J. Morello, M. Wach, D. Gibson, and R. Loria. 2005. A large, mobile pathogenicity island confers plant pathogenicity on Streptomyces species. Molecular Microbiology 55: 1025-1033. 
Klappenbach, J.A., P.R. Saxman, J.R. Cole, and T.M. Schmidt. 2001. Rrndb: The ribosomal RNA operon copy number database. Nucleic Acids Research 29: 181-184.

Kreuze, J.F., S. Suomalainen, L. Paulin, and J.P.T. Valkonen. 1999. Phylogenetic analysis of $16 \mathrm{~S}$ rRNA genes and PCR analysis of the necl gene from Streptomyces spp. causing common scab, pitted scab, and netted scab in Finland. Phytopathology 89: 462-469.

Lambert, D.H., and R. Loria. 1989a. Streptomyces acidiscabies sp. nov. International Journal of Systematic Bacteriology 39: 393-396.

Lambert, D.H., and R. Loria. 1989b. Streptomyces scabies sp. nov; nom rev. International Journal of Systematic Bacteriology 39: 387-392.

Lambert, D.H., A.F. Reeves, R.W. Goth, G.S. Grounds, and E.A. Giggie. 2006. Relative susceptibility of potato varieties to Streptomyces scabiei and S. acidiscabies. American Journal of Potato Research 83: 67-70.

Lees, A.K., D.W. Cullen, L. Sullivan, and M.J. Nicolson. 2002. Development of conventional and quantitative real-time PCR assays for the detection and identification of Rhizoctonia solani AG-3 in potato and soil. Plant Pathology 51: 293-302.

Lehtonen, M.J., H. Rantala, J.F. Kreuze, H. Bang, L. Kuisma, P. Koski, E. Virtanen, K. Vihlman, and J.P.T. Valkonen. 2004. Occurrence and survival of potato scab pathogens (Streptomyces species) on tuber lesions: quick diagnosis based on a PCR-based assay. Plant Pathology 53: 280-287.

Lindholm, P., H. Kortemaa, K. Haahtela, M. Kokkola, M. SalkinojaSalonen, and J.P.T. Valkonen. 1997. Streptomyces spp. isolated from potato scab lesions under nordic conditions in Finland. Plant Disease 81: 1317-1322.

Loria, R., J.A. Kers, and M. Joshi. 2006. Evolution of plant pathogenicity in Streptomyces. Annual Review of Phytopathology 44: 469-487.

Miyajima, K., F. Tanaka, T. Takeuchi, and S. Kuninaga. 1998. Streptomyces turgidiscabies sp. nov. International Journal of Systematic Bacteriology 48: 495-502.

Ohnishi, Y., J. Ishikawa, H. Hara, H. Suzuki, M. Ikenoya, H. Ikeda, A. Yamashita, M. Hattori, and S. Horinouchi. 2008. Genome sequence of the streptomycin-producing microorganism Streptomyces griseus IFO 13350. Journal of Bacteriology 190: 4050-4060.

Park, D.H., J.S. Kim, S.W. Kwon, C. Wilson, Y.M. Yu, J.H. Hur, and C. K. Lim. 2003a. Streptomyces luridiscabiei sp. nov., Streptomyces puniciscabiei sp. nov. and Streptomyces niveiscabiei sp. nov., which cause potato common scab disease in Korea. International Journal of Systematic and Evolutionary Microbiology 53: 20492054.

Park, D.H., Y.M. Yu, J.S. Kim, J.M. Cho, J.H. Hur, and C.K. Lim. 2003b. Characterization of streptomycetes causing potato common scab in Korea. Plant Disease 87: 1290-1296.

Pierzynsk, GM., J.T. Sims, and G.F. Vance. 2005. Soils and environmental quality. CRC.
Powelson, M.L., K.B. Johnson, and R.C. Rowe. 1993. Management of diseases caused by soilborne pathogens. In Potato Health Management, ed. R.C. Rowe, 149-158. St. Paul, MN: American Phytopathological Society.

Qu, X., J.A. Kavanagh, D. Egan, and B.J. Christ. 2006. Detection and quantification of Spongospora subterranea $\mathrm{f}$. sp. subterranea by PCR in host tissue and naturally infested soils. American Journal of Potato Research 83: 21-30.

Qu, X., L.A. Wanner, and B.J. Christ. 2008. Using the TxtAB Operon to Quantify Pathogenic Streptomyces in Potato Tubers and Soil. Phytopathology 98: 405-412.

Sadowsky, M.J., L.L. Kinkel, J.H. Bowers, and J.L. Schottel. 1996. Use of repetitive intergenic DNA sequences to classify pathogenic and disease-suppressive Streptomyces strains. Applied Environmental Microbiology 62: 3489-3493.

Saitou, N., and M. Nei. 1987. The neighbor-joining method: a new method for reconstructing phylogenetic trees. Molecular Biology and Evolution 4: 406-425.

Sambrook, J., F. Fritsch, and T. Maniatis (eds). 1982. Molecular cloning: A laboratory manual. Cold Spring Harbor, New York: Cold Spring Harbor Laboratory.

Song, J., S.-C. Lee, J.-W. Kang, H.-J. Baek, and J.-W. Suh. 2004. Phylogenetic analysis of Streptomyces spp. isolated from potato scab lesions in Korea on the basis of 16S rRNA gene and 16S-23S rDNA internally transcribed spacer sequences. International Journal of Systematic and Evolutionary Microbiology 54: 203-209.

Takeuchi, T., H. Sawada, F. Tanaka, and I. Matsuda. 1996. Phylogenetic analysis of Streptomyces spp. causing potato scab based on 16S rRNA sequences. International Journal of Systematic Bacteriology 46: 476-479.

Tóth, L., M. Maeda, F. Tanaka, and K. Kobayashi. 2001. Isolation and identification of pathogenic strains of Streptomyces acidiscabies from netted scab lesions of potato tubers in Hokkaido (Japan). Acta Microbiologica et Immunologica Hungarica 48: 575-585.

Wanner, L.A. 2004. Field isolates of Streptomyces differ in pathogenicity and virulence on radish. Plant Disease 88: 785-796.

Wanner, L.A. 2006. A survey of genetic variation in Streptomyces isolates causing potato common scab in the United States. Phytopathology 96: 1363-1371.

Wanner, L.A. 2007a. High proportions of nonpathogenic Streptomyces are associated with common scab-resistant potato lines and less severe disease. Canadian Journal of Microbiology 53: 1062-1075.

Wanner, L.A. 2007b. A new strain of Streptomyces causing common scab in potato. Plant Disease 91: 352-359.

Wanner, L.A., K.G. Haynes, C.A. Thill, J. Miller, R.G. Novy, D.L. Corsini, and J.L. Whitworth. 2006. Two years of the National Common Scab Trials of Potato Varieties and Advanced Selections. American Journal of Potato Research 83: 137.

Zhang, Z., S. Schwartz, L. Wagner, and W. Miller. 2000. A greedy algorithm for aligning DNA sequences. Journal of Computational Biology 7: 203-214. 